\title{
Measuring quality of end-of-life communication and decision-making: Do we have this right?
}

\author{
Jeff Myers MD MSEd
}

— Cite as: CMAJ 2017 July 31;189:E978-9. doi: 10.1503/cmaj.170280

See related article at www.cmaj.ca/lookup/doi/10.1503/cmaj.160515

\section{A} recent report from the Institute of Medicine identifies good clinician-patient communication and effective shared decision-making as essential components of a high-quality end-of-life experience, ${ }^{1}$ which should ensure that a person receives end-of-life care that is concordant with his or her values, goals and preferences. Key strategies to achieve this include advance care planning and goals of care discussions. In a linked CMAJ article, Heyland and colleagues respond to the recommendation by the Institute of Medicine to establish measurable, actionable and evidence-based quality standards in end-oflife communication. ${ }^{2}$ They examine the feasibility of implementing a set of quality indicators that address end-of-life communication and decision-making, and report on a methodology to quantify performance for these at the institutional level.

Among a cohort of patients admitted to 1 of 12 teaching hospitals across four provinces, Heyland and colleagues assessed quality indicators that were categorized into three domains: engagement in prehospital advance care planning, elements of goals of care discussions with related decision-making processes about life-sustaining treatments and documentation of these interactions. An overall quality score was tabulated for each hospital and used to compare institutional performance. But are the evaluated indicators the right ones for measuring and ranking institutions' performance on end-of-life communication and decision-making?

Some background may be helpful when interpreting the findings of the linked study. In 2015, an international panel of 52 experts was assembled to identify and rank patient-centred outcomes for advance care planning. ${ }^{3}$ During the first Delphi round, it became clear that panel members did not agree on the definition, purpose, goals and key components of advance care planning. Therefore, the focus for the Delphi process shifted to reaching consensus on these elements. Across health care settings, many hold the view that advance care planning should entail eliciting a patient's preferences for medical treatments in the future, despite clear evidence that the approach is largely ineffective. ${ }^{4,5}$ This is why an understanding of advance care planning as an iterative process that supports an individual to understand and share their personal values and goals, as well as wishes

\section{KEY POINTS}

- Institutional and organizational performance can be measured for end-of-life communication and decision-making, but care must be taken to measure the right indicators.

- The general public defines "goals" as personal life goals and, in the context of advance care planning, values and goals are an expression of a person's overarching philosophies and priorities; this is especially important to remember as practice shifts toward earlier advance care planning.

- Measuring the quality of advance care planning and goals of care discussions will require indicators that reflect processes that incorporate personal values and life goals.

regarding the outcomes of care in the future, has supplanted the outdated view. The expert panel noted that the public defines goals as personal life goals and, in the context of advance care planning, values and goals are an expression of a person's overarching philosophies and priorities. ${ }^{3}$ The panel's consensus was that the purpose of advance care planning is to address overall values and personal life goals. They went on to recommend that, when specific treatment decisions are being made, clinicians should work with patients or decision-makers to use the overall values and personal care goals of the individual uncovered during advance care planning to help guide decision-making.

In the linked article, the assessment of prehospital advance care planning focuses almost exclusively on discussions of patient preferences for medically appropriate life-sustaining treatments. Indeed, an institution received negative ratings for this domain if preferences for life-sustaining treatments were not specifically addressed. This narrow definition does not align with the broader definition of advance care planning outlined earlier. However, the problem is not as straightforward as simple misalignment of definitions. As practice moves toward earlier advance care planning, as has been recommended, ${ }^{1}$ a focus on specific life-sustaining treatments when advance care planning will make little sense; patients will have scant appreciation of the context in which such life-sustaining treatments will be necessary, because they will be less advanced in the course of their illness. 
Clarifying the orientation of goals when advance care planning as being a patient's personal life goals and not the goals of medical treatments has implications for determining the quality of a goals of care discussion. As a precursor to decision-making, an effective goals of care discussion may simply be a statement of a personal life goal as it relates to consent for a treatment decision. The following is an example:

Mr. M's primary goal is attending his daughter's wedding. Today, he consents to continuing the current treatment plan until then, when we will revisit.

The possible treatment plans in this scenario are diverse but can include high-stakes interventions such as continuing dialysis or systemic cancer treatment. Separating goals of care discussions and decision-making into distinct processes, with the purpose of the goals of care discussions being to clarify personal life goals, may make decision-making more likely to be both shared and personcentred. Furthermore, recent qualitative evidence from focus groups of patients in primary care who have serious illness suggests that potential outcomes of treatments are more likely to matter to a patient than the treatments themselves. ${ }^{6}$ For both advance care planning and goals of care discussions, more actionable information may emerge by asking what is most hoped for or feared than asking if a person wants or does not want specific treatments.

An important element of both advance care planning and goals of care discussions that is seldom addressed is the challenge that most patients with serious illness do not fully appreciate or understand their illness as incurable and progressive. ${ }^{7,8}$ Irrespective of the reason for this (e.g., adequate information is not provided, information is not understood by the patient or cultural barriers prevent the patient from conceiving of the illness trajectory), the possibility remains that a decision regarding life-sustaining treatment may not be indicative of a patient or decision-maker who is adequately informed. Assessment of patient or decision-maker understanding of the illness or diagnosis may be an important indicator to consider when reviewing the quality of advance care planning and discussions about goals of care.
The linked article sends a clear and important message that institutional and organizational performance can be measured for end-of-life communication and decision-making. However, getting end-of-life communication and decision-making right will require that clinicians evolve their understanding of advance care planning and embrace a patient-centred approach. There is still work to be done to ensure that the end-of-life care provided to a patient is concordant with his or her personal values and life goals. Measuring the quality of those interactions will require indicators that reflect these criteria.

\section{References}

1. Dying in America: improving quality and honoring individual preferences near the end of life. Washington: The National Academies Press; 2014

2. Heyland DK, Dodek P, You JJ, et al. Validation of quality indicators for end-oflife communication: results of a multicentre survey. CMAJ 2017;189: E980-9.

3. Sudore RL, Lum HD, You JJ, et al. Defining advance care planning for adults: a consensus definition from a multidisciplinary Delphi panel. J Pain Symptom Manage 2017:53:821-32.

4. Sudore RL, Fried TR. Redefining the "planning" in advance care planning: preparing for end-of-life decision making. Ann Intern Med 2010;153:256-61.

5. Lum HD, Sudore R, Bekelman DB. Advance care planning in the elderly. Med Clin North Am 2015;99:391-403.

6. McMahan RD, Knight SJ, Fried TR, et al. Advance care planning beyond advance directives: perspectives from patients and surrogates. J Pain Symptom Manage 2013;46:355-65.

7. Weeks JC, Catalano PJ, Cronin A, et al. Patients' expectations about effects of chemotherapy for advanced cancer. N Engl J Med 2012;367:1616-25.

8. Lefkowitz A, Henry B, Bottoms J, et al. Comparison of goals of care between hemodialysis patients and their health care providers: a survey. Can J Kidney Health Dis 2016;3:2054358116678207.

Competing interests: Jeff Myers was one of the panelists who were assembled to identify and rank the quality indicators used in the linked study.

Affiliation: Department of Family and Community Medicine, Division of Palliative Care, Sunnybrook Health Sciences Centre, Toronto, Ont.

This article was solicited and has not been peer reviewed.

Correspondence to: Jeff Myers, jeff.myers@sunnybrook.ca 